\title{
Bladder Cancer Invasion Is Mediated by Mammalian Target of Rapamycin Complex 2-Driven Regulation of Nitric 0xide and Invadopodia Formation
}

Divya Sahu, ${ }^{*}$ Jianya Huan, ${ }^{\dagger}$ Huawei Wang, ${ }^{*}$ Debashis Sahoo, ${ }^{*}$ Darren E. Casteel, ${ }^{\ddagger}$ Richard L. Klemke, ${ }^{*}$ Gerry R. Boss, ${ }^{\ddagger}$ and Donna E. Hansel

From the Departments of Pathology \& Laboratory Medicine* and Medicine ${ }^{\ddagger}$ University of California at San Diego, La Jolla, California; and the Department of Pathology \& Laboratory Medicine, ${ }^{\dagger}$ Oregon Health \& Science University, Portland, Oregon

\author{
Accepted for publication \\ August 6, 2021. \\ Address correspondence to \\ Donna E. Hansel, M.D., Ph.D., \\ Department of Pathology \& \\ Laboratory Medicine, Oregon \\ Health \& Science University, \\ 3181 Sam Jackson Park Rd., \\ OHSU Pathology, L-113, Port- \\ land, OR 97239. E-mail: \\ hansel@ohsu.edu.
}

\begin{abstract}
Bladder cancer invasion depends on mammalian target of rapamycin complex 2 (mTORC2) activity, although the downstream mTORC2 effectors that mediate this effect have not been fully defined. One potential downstream effector is the arginine derivative nitric oxide (NO). This study identified a stageassociated increase in the expression of the NO-generating enzymes endothelial NO synthase (eNOS) and inducible NOS (iNOS) in human bladder cancer. Reduction of NOS activity by pharmacologic inhibition or silencing of NOS enzymes reduced cancer cell invasion, with similar effects observed using the NO scavenger cobinamide. By contrast, enhanced invasion was seen with the NO donor DetaNONOate and an analog of the downstream NO second messenger cGMP. Next, NOS expression was evaluated in invadopodia, which are cellular protrusions that form the invasive tips of cancer cells. Invadopodia were enriched in both iNOS protein and mTORC2 activity, and invadopodia formation was increased by Deta-NONOate and decreased by cobinamide and ablation of mTORC2 activity. Additionally, mTORC2 increased expression of iNOS. Using a zebrafish model, injection of iNOS- or rictor-silenced cells reduced the frequency of bladder cancer cell metastasis in zebrafish. These results indicate that mTORC2 can mediate bladder cancer cell invasion through increased iNOS expression, resulting in increased NO and CGMP production in invadopodia and further propagation of invadopodia formation. (Am J Pathol 2021, 191: 2203-2218; https://doi.org/10.1016/j.ajpath.2021.08.002)
\end{abstract}

Bladder cancer affects more than half a million people in the United States. ${ }^{1}$ Invasive behavior in bladder cancer drives diseased progression and correlates to increased cancer stage and reduced disease-specific survival. ${ }^{2}$ Specifically, the 5-year relative survival rate is $88 \%$ for patients with stage I bladder cancer but only $15 \%$ for patients with stage IV disease. ${ }^{3}$ One opportunity to improve survival in patients with advanced bladder cancer may include therapeutics development focused on discovery of new invasive mechanisms relevant to this disease.

Current understanding of invasion in bladder cancer includes a prominent central role for the mammalian target of rapamycin complex 2 (mTORC2) in this process, with effectors of mTORC2 such as RhoGTPases ${ }^{4}$ and caveolin- $1,{ }^{5,6}$ involved in regulating downstream effects. Other potential downstream mediators of $\mathrm{mTORC} 2$ may include arginine and the arginine derivative nitric oxide (NO), which are increased in invasive bladder cancer and affect invasion in other model systems. ${ }^{7,8}$ A recent analysis of arginine and its synthesizing enzyme argininosuccinate synthase 1 in bladder cancer indicated that extracellular arginine was required for survival and that bladder cancer cells that lack arginine-synthesizing capacity could be targeted by arginine-degrading enzymes. ${ }^{9}$ However, the role

Supported by a Prevent Cancer Foundation Fellowship (D.S.).

Disclosures: None declared. 
of arginine or NO in mTORC2-mediated invasion was not examined and represents the focus of the current study.

NO is a highly diffusible small molecule that is generated from arginine by a family of synthesizing enzymes, including neuronal nitric oxide synthase (nNOS; NOS1), inducible nitric oxide synthase (iNOS; NOS2), and endothelial nitric oxide synthase (eNOS; NOS3). Increased expression of NOS enzymes has been found in patient bladder cancer tissue, ${ }^{10-17}$ and NO breakdown products have been detected in the urine of patients with bladder cancer. ${ }^{18,19}$ However, mechanistic studies on NOS enzymes or NO in bladder cancer invasion have not been performed in detail. Within other cancer models, NO has indicated both protumor and antitumor effects. Examples of protumor effects include free radical DNA damage, suppression of DNA repair enzymes, production of protumorigenic neovasculature ingrowth, and enhancement of cancer cell proliferation. ${ }^{8,18,20} \mathrm{NO}$ also increases cancer cell invasion and may act upstream of Rho GTPases, ${ }^{21,22}$ which are small signaling $\mathrm{G}$ proteins that regulate cytoskeletal dynamics and can be activated by mTORC2 in bladder cancer. ${ }^{4,23}$

The current study examined the role of the arginine derivative $\mathrm{NO}$ in bladder cancer cell invasion and tested its relationship to mTORC2 signaling. Given that mTORC2 promotes invasive behavior, analysis of NO and mTORC2 function in invadopodia, which are organized, directional, invasive outgrowths of cancer cells, was incorporated. ${ }^{24}$ Finally, the effects of mTORC2 activity and $\mathrm{NO}$ in a Zebrafish metastasis model were tested to determine whether these signaling factors can affect disseminated spread of bladder cancer cells. The results of this study indicate that $\mathrm{NO}$ is a novel downstream effector of mTORC2 activity that regulates invadopodia formation and bladder cancer cell invasion and dissemination.

\section{Materials and Methods}

\section{Cell Lines and Chemical Treatment}

RT4, UM-UC-3, T24, and J82 cell lines were purchased from ATCC (Manassas, VA), with authentication by STR analysis (IDEXX BioResearch, Columbia, MO). RT112 cells were a gift from Dr. P. Szlosarek (Queen Mary University of London, London, UK), with authentication by STR analysis. ${ }^{25}$ UROtsa cells were a gift from Deutsche Sammlung fur Mikroorganismen und Zellkultur (Braunschweig, Germany), with authentication by STR analysis (Leibniz Institute, Deutsche Sammlung fur Mikroorganismen und Zellkultur). ${ }^{26}$ Cells were grown in RPMI 1640 medium (Gibco, Life Technologies, Grand Island, NY) supplemented with $10 \%$ fetal bovine serum (Gibco). All cell lines were maintained at $37^{\circ} \mathrm{C}$ in $5 \% \mathrm{CO}_{2}$ and used up to passage 20. L-Arginine, L-Name, and $1400 \mathrm{~W}$ were purchased from Sigma-Aldrich (St. Louis, MO), 1H-[1,2,4] oxadiazolo[4,3-a]quinoxalin-1-one (ODQ) from Cayman Chemical (Ann Arbor, MI), and Deta-NONOate from
Abcam (Cambridge, MA). Aquahydroxocobinamide (cobinamide) was prepared as described. ${ }^{27}$ All chemical stock solutions were freshly prepared through dilution in serumfree media with the exception of ODQ, which was diluted in dimethyl sulfoxide.

\section{Gene Silencing and Cell Transfection}

For transient transfection experiments, siGENOME SMARTpool gene-specific siRNA containing four pooled siRNAs per target was used for eNOS (catalog number M006490-00), iNOS (catalog number M-009240-01), and rictor (catalog number M-016984-02) silencing (GE Dharmacon, Lafayette, CO). siGENOME pooled nontargeting control (NTC) siRNA 1 (catalog number D-001206-13) was used for control comparison (GE Dharmacon, Lafayette, CO). Transient transfections were performed using Lipofectamine RNAiMAX Reagent (Invitrogen, Carlsbad, CA). For stable transfection experiments, gene-specific MISSION shRNA lentiviral particles (Sigma-Aldrich) were used for stable silencing of eNOS, iNOS, and rictor, with NTC shRNA as control. Stable silencing was performed using transfection with $8 \mu \mathrm{g} / \mathrm{mL}$ of hexadimethrine bromide (Sigma-Aldrich), and stable populations of transfected cells were generated through selection with $1 \mu \mathrm{g} / \mathrm{mL}$ of puromycin (Sigma-Aldrich).

\section{Immunoblot Analysis}

Whole cell lysates were extracted with radioimmunoprecipitation assay buffer containing protease and phosphatase inhibitor cocktails (Roche, Basel, Switzerland) and subjected to Western blot analysis, as previously described. ${ }^{4}$ In brief, proteins were separated on $4 \%$ to $15 \%$ gradient SDS-PAGE gels (Bio-Rad Laboratories, Inc., Hercules, CA) and transferred to supported nitrocellulose membranes (Bio-Rad Laboratories, Inc.) using a Bio-Rad Mini-PROTEAN Tetracell system. After transfer, blots were incubated in a $5 \%$ bovine serum albumin, $0.1 \%$ Tween 20, and Tris-buffered saline blocking solution for 1 hour. Primary antibodies included eNOS (1:500; catalog number ab5589, Abcam), iNOS (1:500; catalog number ab3523, Abcam), rictor (1:1000; Cell Signaling Technology, Danvers, MA, catalog number 2140), phospho-AKT Ser473 (1:1000; Cell Signaling Technology, catalog number 4060), total AKT (1:1000; Cell Signaling Technology, catalog number 4685), phospho-S6 Ser235/236 (1:1000; Cell Signaling Technology, catalog number 4858), total S6 (1:1000; Cell Signaling Technology, catalog number 2217), histone H3 (1:1000; Cell Signaling Technology, catalog number 9715), and Rac-1 (1:1000; Thermo Scientific, catalog number 1862341). Lipopolysaccharide-treated raw 264.7 macrophages and endothelial cell lysates were used as positive controls for iNOS and eNOS antibodies, respectively. Blots were incubated with primary antibody overnight at $4^{\circ} \mathrm{C}$, followed by incubation with horseradish peroxidase-conjugated anti-rabbit or anti-mouse secondary 
antibodies (1:10,000; Jackson ImmunoResearch Laboratories, Inc., West Grove, PA) for 1 hour at room temperature. Blots were developed using the Enhanced Chemiluminescence Kit (Pierce, Thermo Fisher Scientific, Waltham, MA) followed by autoradiography. Because several antibodies needed to be probed, duplicate sets of samples from the same experiment were run and probed with the different antibodies.

\section{Cell Migration Assay}

Cell migration was analyzed using the modified scratch wound assay to limit cellular disruption, as described previously. ${ }^{4}$ In brief, a thin strip of polydimethylsiloxane (Sylgard 184 silicone elastomer, Dow Corning Corp., Midland, MI) was placed in the center of each plate over which cells were plated. After adherence, cells were serum starved overnight in serum-free media. Peels were then carefully removed, and cells were allowed to migrate for 24 hours. Serum-free conditions represent negative control. The peel area was imaged at 0 hour and 24 hours using an Olympus CKX41 inverted microscope (Tokyo, Japan) equipped with a Nikon D3200 DSLR digital camera (Tokyo, Japan).

\section{Cell Invasion Assay}

Cell invasion was assessed using growth factor-reduced matrigel invasion chambers (Corning Inc., Corning, NY), according to the manufacturer's instructions. In brief, cells were serum starved overnight and plated in serumfree media onto the upper chamber and allowed to invade for 24 hours. The lower chamber was filled with RPMI 1640 media that contained $10 \%$ or $0.1 \%$ fetal bovine serum to serve as a chemoattractant. Chemicals or inhibitors were added to both chambers or only the lower chamber as indicated. At the completion of the experiment, membranes were fixed and permeabilized in icecold methanol. Noninvading cells were gently removed by cotton swab and the membrane was subsequently mounted on a slide with Prolong Gold Antifade reagent with DAPI (Molecular Probes, Life Technologies, Carlsbad, CA). Images of at least six independent fields were obtained using a Leica DM IRE2 inverted fluorescent microscope (Leica Microsystems, Buffalo Grove, IL) with an ORCA-100 digital camera (Hamamatsu Corp., Sewickley, PA) using SimplePCI software (version 6; Hamamatsu Corp.). The number of invading cells were counted manually.

\section{Immunofluorescence Staining}

Cells were plated on four-well chamber slides (Nunc, Labtek, Thermo Fisher Scientific, Denver, CO). After treatment, cells were fixed in fresh $4 \%$ formaldehyde at room temperature for 15 minutes, permeabilized in $0.1 \%$ Triton X100 in phosphate-buffered saline (PBS), and blocked with $10 \%$ normal goat serum. Cells were incubated with a 1:50 dilution of eNOS (Abcam, catalog number ab5589) or iNOS (Abcam, catalog number ab3523) antibody overnight at $4^{\circ} \mathrm{C}$. After incubation, cells were washed and incubated with anti-rabbit Alexa-conjugated secondary antibodies (Invitrogen), followed by incubation with Actin-Green (Invitrogen). Slides were coverslipped using the Prolong Gold Antifade reagent (Cell Signaling Technology) that contained DAPI. Imaging was performed using an inverted Leica DM IRE2 fluorescent microscope (Leica Microsystems).

\section{Invadopodia Induction and Analysis}

Invadopodia were induced as previously described. ${ }^{28}$ In brief, serum-starved cells were plated on top of 3.0- $\mu \mathrm{m}$ polycarbonate membrane filters (Corning Inc.) in serum-free media and allowed to adhere for 2 to 2.5 hours. The filters were then transferred to transwell migration chambers that contained 10\% FBS in RPMI 1640 medium. Invadopodia were allowed to develop for 1 hour. Filters were next rinsed in ice-cold PBS, fixed in ice-cold methanol for 30 minutes, and washed with cold PBS. The cell bodies from the top of the filter were carefully wiped off with a cotton-tipped swab, where the invadopodia on the lower surface of the filter was scraped off with a small plastic cell scraper. The harvested cell bodies and collected invadopodia were washed with cold PBS, lysed with lysis buffer that contained 1\% SDS, 2 $\mathrm{mmol} / \mathrm{L}$ sodium orthovanadate, $1 \mathrm{mmol} / \mathrm{L}$ phenylmethylsulfonyl fluoride, and a protease and phosphatase inhibitor cocktail (Roche), and then centrifuged at $45,000 \times g$ for 15 minutes. ${ }^{28}$ Protein concentration of the supernatant was determined using the Pierce BCA Protein Assay Kit (Thermo Fisher Scientific). Immunofluorescence of invadopodia was performed by fixing filters in $4 \%$ formaldehyde and performing immunostaining as described above. Quantitation of staining intensity was performed using ImageJ version 2.1.0 (NIH, Bethesda, MD; http:// imagej.nih.gov/ij).

\section{cGMP Analysis}

cGMP analysis was performed using the Cyclic GMP XP Assay Kit (Cell Signaling Technology) per the manufacturer's instructions. In brief, equal quantities of treated cell lysates were incubated with cGMP horseradish peroxidase conjugate in wells that contained immobilized cGMP antibody for 3 hours at room temperature. After washing, the TMB substrate was added to develop color, the reaction terminated by adding STOP solution, and the plate read at $450 \mathrm{~nm}$ using a SpectraMax M2 ${ }^{\mathrm{e}}$ Microplate Reader (Molecular Devices, San Jose, CA) with SoftMax Pro software version 6.3. Sample cGMP concentrations were calculated from a standard curve run parallel to sample.

\section{Cell Viability Assay}

Cell viability was evaluated with the Vybrant MTT [3-(4, 5-dimethylthiazol-2-yl)-2,5-diphenyltetrazolium 


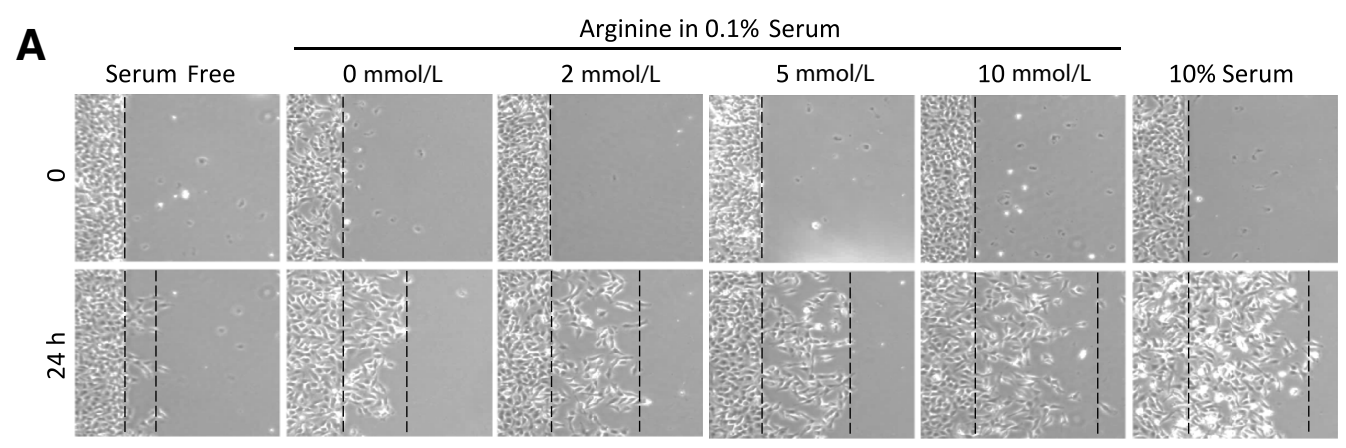

B

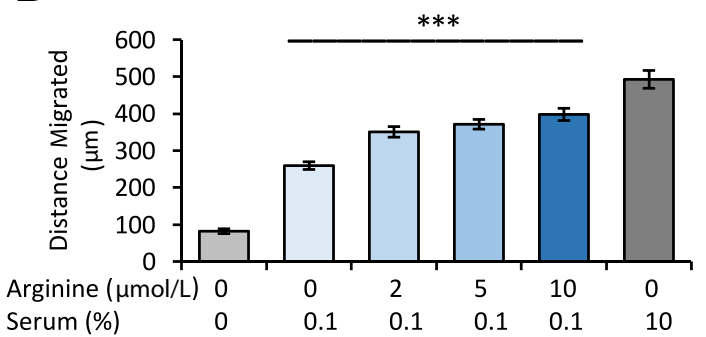

C

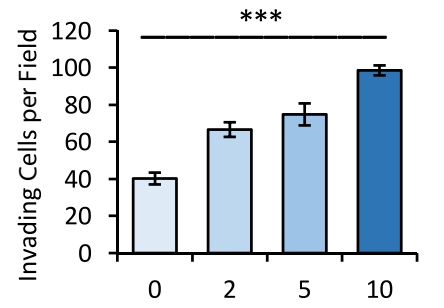

Arginine in $0.1 \%$ Serum $(\mu \mathrm{mol} / \mathrm{L})$

D

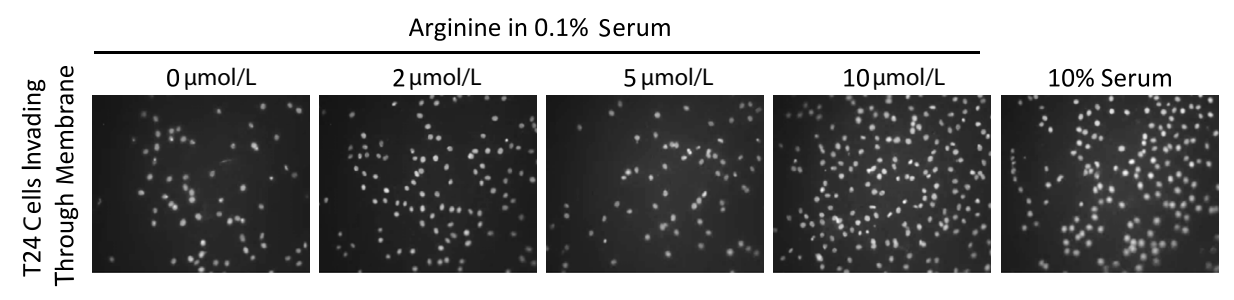

E

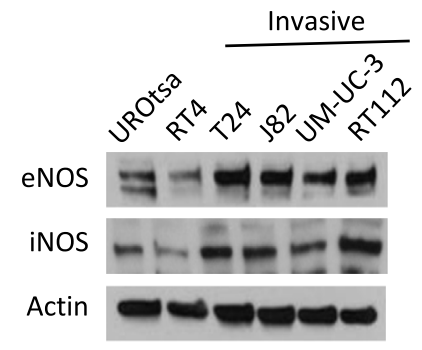

$\mathbf{F}$

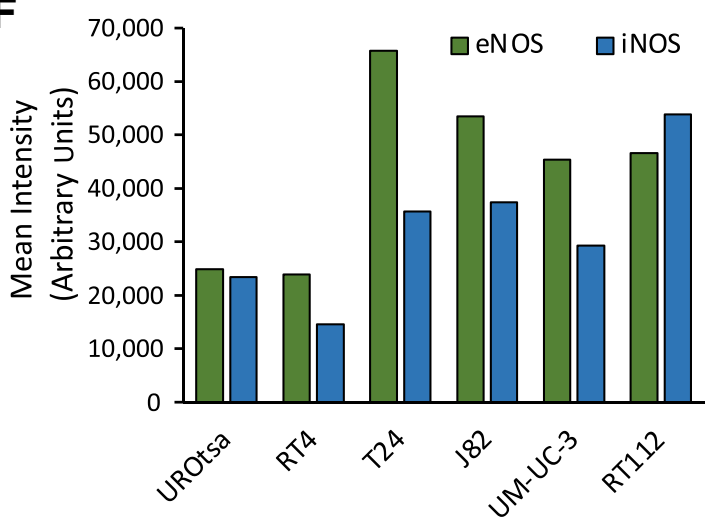

Figure 1 Exogenous arginine increases bladder cancer migration and invasion. A: Representative images of modified scratch migration assay to assess twodimensional cell migration in response to arginine in $0.1 \%$ serum-containing media. The first dotted line indicates the cell migration at 0 hour, and the second dotted line indicates the cell migration at 24 hours. B: Quantitation shows a dose-dependent increase in T24 migration after arginine addition. C: Dosedependent increase in transwell invasion in T24 cells after arginine addition. D: Representative images of DAPI-stained cells invading through Matrigelcoated invasion chambers. E: Immunoblot assay of endothelial nitric oxide synthase (eNOS) and inducible nitric oxide synthase (iNOS) in a panel of bladder cell lines. F: Quantitation shows increased expression of eNOS and iNOS in invasive cell lines compared with noninvasive cell lines. Data are expressed as means $\pm \operatorname{SEM}(\mathbf{B}, \mathbf{C}$, and $\mathbf{F}) . n=3 .{ }^{* * *} P<0.001$ (analysis of variance). Original magnification, $\times 100(\mathbf{A}, \mathbf{D}$, and $\mathbf{E})$.

bromide] Cell Proliferation Assay Kit (Molecular Probes, Thermo Fisher Scientific) per the manufacturer's instructions. Briefly, cells were plated onto 96-well plates and treated for 24 hours. Absorbance readings were measured at $540 \mathrm{~nm}$ using a SpectraMax $\mathrm{M} 2{ }^{\mathrm{e}}$ Microplate Reader with SoftMax Pro software version 6.3. Results for test samples were normalized to those of untreated samples. 


\section{Zebrafish Xenograft Model}

The study was approved by the University of California, San Diego Institutional Animal Care and Use Committee. NTC-silenced UM-UC-3 cells were fluorescently labeled using the green CMFDA (5-chloromethylfluorescein diacetate) Green dye (Molecular Probes), and iNOS or rictor-shRNA stable silenced cells were labeled with the red CMTPX dye (Molecular Probes) per manufacturer instructions. Control and target-specific silenced cells were mixed in a 1:1 ratio before injection. Zebrafish (Danio rerio) wild-type $\mathrm{AB}$ embryos were derived through standard mating conditions and staged by hours post fertilization. At 48 hours post fertilization, embryos were dechorionized, anesthetized with tricaine, and microinjected with 200 to 300 mixed control and target-specific human tumor cells in $50 \mathrm{~nL}$ of PBS into the perivitelline cavity of each embryo. ${ }^{29}$ After injection, embryos were transferred to a $34^{\circ} \mathrm{C}$ incubator and subsequently imaged after 24 hours using a Nikon c1-si confocal microscope or inverted Leica DM IRE2 fluorescent microscope. The number of extravasated cells outside the vasculature in the tail region were quantified. ${ }^{29,30}$ At least 10 zebrafish were analyzed per experiment.

\section{Patient Specimens and Tissue Immunohistochemistry}

The study was approved by the University of California, San Diego Institutional Review Board. Patients with invasive bladder cancer were identified through a database search using an institutional review board-approved protocol. All cases were re-reviewed by the corresponding author (D.E.H.). Of the 89 cystectomy cases included for evaluation, pathologic stage included pT2 [19 (20\%)], pT3 [62 (70\%)], and pT4 [6 (7\%)]. Variant morphology was excluded, including cases with divergent differentiation. Patients included 71 men and 18 women with a mean age of 64 years (range, $43-85$ years) and a mean follow-up of 25.3 months (range, 1 to 83 months; median, 18 months). Estimated median overall survival and recurrence-free survival was 21.5 months (95\% CI, 15.4-29.5) and 18.5 months (95\% CI, 13.0-26.9), respectively. Forty-six patients had nonmetastatic disease, and 43 patients had metastatic disease; in the latter, paired lymph node metastasis was used for comparison. In addition, 10 specimens of normal urothelium were included for study and obtained from patients with no prior or subsequent history of bladder cancer. ${ }^{31}$ Specimens included clinically archived, formalin-fixed, paraffin-embedded material from biopsy, transurethral resection, and resection of bladder cancers. Immunohistochemistry was performed as previously described. ${ }^{4}$ Noninvasive, invasive high-grade, and metastatic high-grade bladder cancers were evaluated. In addition, normal urothelium from patients without a history of bladder cancer was used as a normal control. All specimens were rereviewed by the corresponding author (D.E.H.) for diagnostic accuracy. Sections $4 \mu \mathrm{m}$ thick were cut onto Fisher plus glass slides (Thermo Fisher Scientific), with one slide used for hematoxylin and eosin stain and the remaining sections used for immunohistochemical analysis. Four tumor regions per specimen were used for tissue microarray generation.

For immunohistochemical stains, slides were subjected to antigen retrieval in a Tris-EDTA $\mathrm{pH} 9.0$ buffer, followed by blocking with $10 \%$ normal goat serum for 1 hour at room temperature. Slides were then incubated with primary antibodies against eNOS (1:500) or iNOS (1:1100) (Abcam) overnight at $4^{\circ} \mathrm{C}$. The next day, slides were washed and incubated in secondary antibody for 1 hour at room temperature using a rabbit-specific horseradish peroxidase/DAB detection immunohistochemistry kit (Abcam), followed by chromogenic development according to the manufacturer's instructions. Slides were counterstained with Hematoxylin II and Bluing Reagent and visualized by light microscopy. Samples were treated without primary antibody as the negative control. Endothelial cells within the samples served as the positive control for eNOS, whereas lung tissue used for orientation within the tissue microarray served as positive control for iNOS antibody, respectively (data not shown). Analysis of immunohistochemical intensity was scored as 0 (absent staining), $1+$ (weak staining), $2+$ (moderate staining), and $3+$ (intense staining). Samples with staining of 2 or $3+$ were classified as having high expression compared with those with 0 or $1+$ staining. Slides were scored by a clinician who is trained in bladder cancer pathology (D.S.), and a subset was verified, blinded to targets, by a clinician who is a urologic pathologist with expertise in bladder cancer (D.E.H.). Because the samples were part of a tissue microarray and not whole slides, stage information was not apparent during scoring, and the persons reviewing the slides were blinded to stage data (D.E.H.).

\section{Statistical Analysis}

One-way analysis of variance was performed throughout the experiments for the comparison among multiple sample groups derived from the same source but with different treatment conditions. The $t$-test was performed using the paired test for zebrafish experiments. The MannWhitney test was used for NOS immunohistochemical analysis.

\section{Results}

Arginine Increases Bladder Cancer Cell Migration and Invasion with Highly Invasive Bladder Cancer Cells Showing Increased NOS Enzyme Expression

Prior studies indicate that arginine is important for bladder cancer cell survival, ${ }^{32}$ although motility effects were not examined in detail. Given that the arginine metabolite NO 
has been identified as promotility factor in other systems, whether arginine and NO would have a similar effect in bladder cancer was investigated. Using a two-dimensional scratch/polydimethylsiloxane motility assay, ${ }^{33}$ the effect of exogenous arginine was first measured on the migration of T24, J82, and RT112 bladder cancer cells. Application of $2 \mathrm{mmol} / \mathrm{L}, 5 \mathrm{mmol} / \mathrm{L}$, and $10 \mathrm{mmol} / \mathrm{L}$ arginine in reduced serum media to T24 cells showed a dose-dependent increase in cell migration at 24 hours to $135 \%, 143 \%$, and $153 \%$ of the control $(P<0.001)$, respectively (Figure 1, A and B). J82 and RT112 cells also had a dose-dependent increase in cell migration to $140 \%, 171 \%$, and $185 \%$ for J82 cells $(P<0.001)$ (Supplemental Figure S1A) and $106 \%, 126 \%$, and $130 \%$ for RT1132 cells $(P<0.001)$ (Supplemental Figure S1B) of the control, respectively. Serum-starved and serum-stimulated cells were used as negative and positive controls, respectively. Next, the effect of arginine on invasion was measured using a Matrigel-coated transwell assay. Addition of $2 \mathrm{mmol} / \mathrm{L}, 5$ $\mathrm{mmol} / \mathrm{L}$, or $10 \mathrm{mmol} / \mathrm{L}$ arginine to the media increased transwell invasion to $166 \%, 186 \%$, and $245 \%$, of baseline, respectively $(P<0.001)$ (Figure $1 C)$. Representative images of transmembrane invading cells are shown in Figure 1D.

Given that arginine can increase migration and invasion, whether NOS enzymes and resultant NO production were responsible for these effects was evaluated next. Analysis of mRNA expression of NOS enzymes using the publicly available database The Human Protein Atlas (https://www. proteinatlas.org, last accessed May 24, 2021) ${ }^{34}$ found an expression level of 0 fragments per $284 \mathrm{~kb}$ of exon per million reads for nNOS (http://www.ncbi.nlm.nih.gov; accession number ENSG00000089250), 1.7 fragments per $284 \mathrm{~kb}$ of exon per million reads for eNOS (http://www. ncbi.nlm.nih.gov; accession number ENSG00000164867), and 1.0 fragments per $284 \mathrm{~kb}$ of exon per million reads for iNOS (http://www.ncbi.nlm.nih.gov; accession number ENSG00000007171). The expression of eNOS and iNOS proteins in bladder cancer cell lines was confirmed using immunoblot, with higher protein expression levels present in the T24, J82, UM-UC-3, and RT112 bladder cancer cells compared with those in the less invasive RT4 bladder cancer cells and the normal urothelium-derived UROtsa cells ${ }^{26}$ (Figure 1, E and F).

\section{eNOS and iNOS Enzymes Mediate Bladder Cancer Migration and Invasion through Effects on Downstream NO and cGMP Signaling}

Given the increased expression of eNOS and iNOS expression in invasive bladder cancer tissue and cells, whether NOS expression levels could affect bladder cancer cell invasion was tested next. To abrogate the expression of eNOS and iNOS, selective silencing was used with pooled isoform-specific siRNA for eNOS (si-eNOS) and iNOS (si-iNOS). Immunoblot confirmed reduced eNOS and iNOS protein expression in NOS-silenced T24, J82, and RT112 cells compared with cells transfected with NTC siRNA (si-NTC) (Figure 2A). Transwell invasion assay indicated a reduction in invasion to $15 \%(P<0.001)$ in the eNOS-silenced T24 cells and a reduction in invasion to $18 \%(P<0.001)$ as compared to the in eNOS-silenced J82 cells si-NTC transfected cells (Figure 2, B-D). iNOS silencing also reduced invasion in $\mathrm{T} 24$ and $\mathrm{J} 82$ cells to $32 \%(P<0.001)$ and $58 \%(P<0.001)$ as compared to that in si-NTC cells, respectively. No differences in cell attachment to the transwell membrane were evident between control and test conditions by crystal violet staining (Supplemental Figure S2). Given the low baseline invasion associated with RT112 cells, this cell line was not included for further invasion analysis. ${ }^{35,36}$ Additional experiments assessing two-dimensional motility using the modified scratch migration assay indicated a reduction in migration of both eNOS- and iNOS-silenced T24 cells at 24 hours (Figure 2E). Further quantification of migration effects in this assay in T24, J82, and RT112 cell lines found a significant reduction $(P<0.001)$ in cell migration in all eNOS- and iNOS-silenced bladder cancer cells (Figure 2, $\mathrm{F}-\mathrm{H})$.

The effects of NOS enzyme activity on bladder cancer cell migration and invasion were confirmed using pharmacologic inhibition of NOS enzymes. Addition of the pan-NOS inhibitor L-Name or the iNOS-specific inhibitor $1400 \mathrm{~W}$ decreased bladder cancer migration to $69 \%$ $(P=0.0001)$ and $67 \%(P=0.0002)$ of serum-treated control cells, respectively (Figure 2I). Inhibition of NOS enzymes could be reversed through application of the NO donor Deta-NONOate, with migration restored to $86 \%$ $(P=0.04)$ and $88 \%(P=0.02)$ of the control cells, respectively.

To confirm that NO activity contributed to the effects on bladder cancer cell migration and invasion, soluble guanylyl cyclase activity and formation of cGMP, the downstream effectors of the NO receptor, were examined. ODQ, an inhibitor of soluble guanylyl cyclase, decreased cell migration to $40 \%$ of the control $(P<0.001)$. This inhibition could be reversed by the addition of a cell permeable cGMP analog, 8 -cPT-cGMP, which restored cell migration to $63 \%$ of the control $(P=0.0002)$ (Figure 2I).

\section{eNOS and iNOS Are Upregulated in Human Bladder Cancer Progression}

To confirm that eNOS and iNOS are relevant in the setting of human bladder cancer, immunohistochemical analysis of eNOS and iNOS expression was performed in patient specimens with normal urothelium and bladder cancer specimens of increasing grade and stage. eNOS and iNOS expression was restricted to the focal expression in the outermost umbrella cell layer in normal urothelium ${ }^{37}$ (Figure 3A). Whereas iNOS had an increase in protein expression in noninvasive papillary urothelial carcinomas that persisted into the 
A

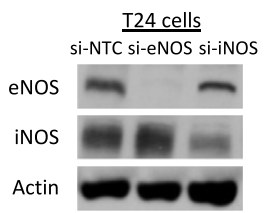

$\underline{82 \text { cells }}$

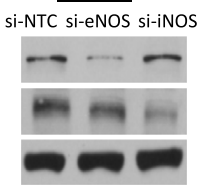

RT112 cells

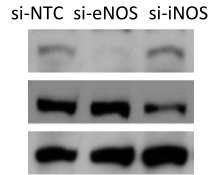

B

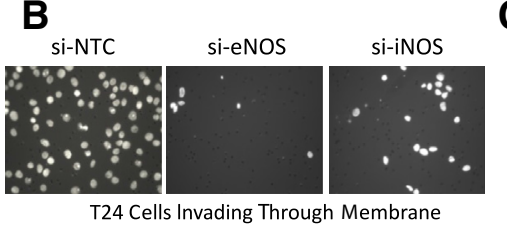

E

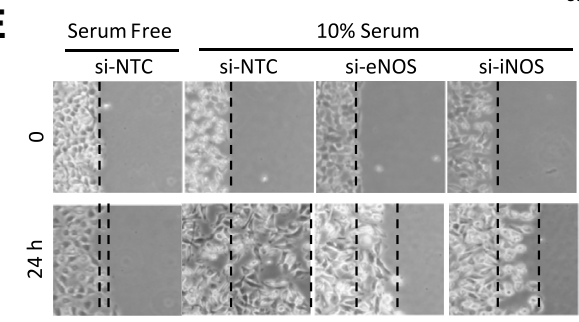

G

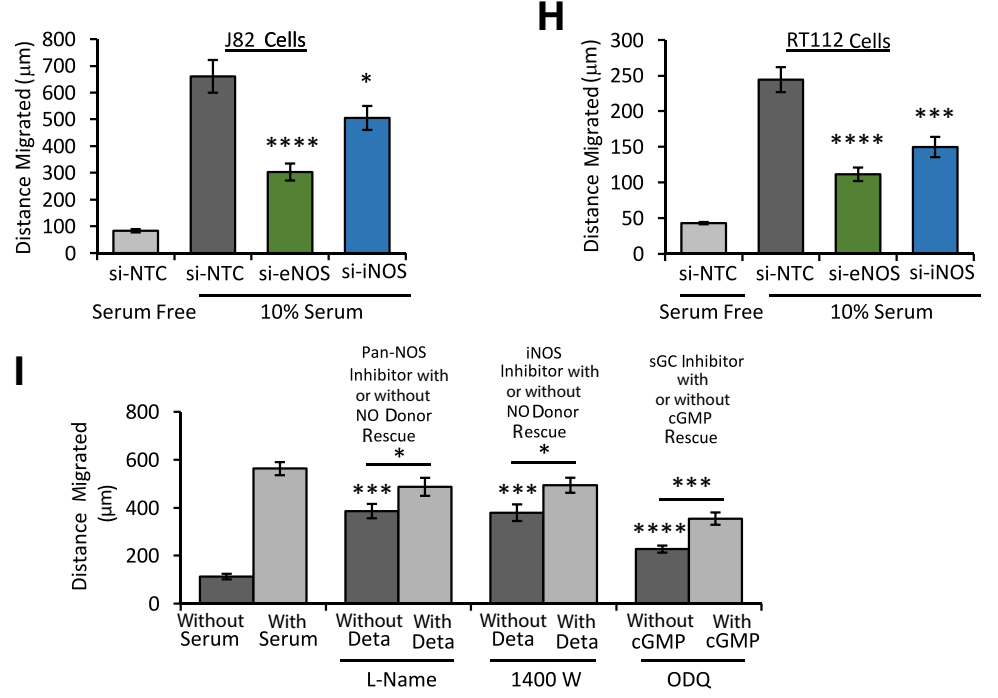

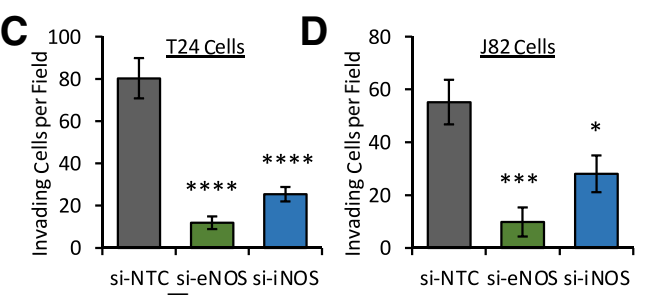

$\mathbf{F}$

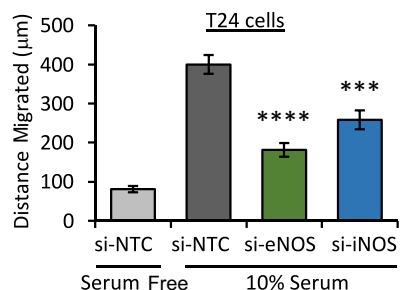

H

Figure 2 Endothelial nitric oxide synthase (eNOS) and inducible nitric oxide synthase (iNOS) regulate motility of bladder cancer cells. A: Immunoblots of T24, J82, and RT112 cells transfected with nontargeting control siRNA (si-NTC), eNOS siRNA (si-eNOS), and iNOS siRNA (si-iNOS)-show target-specific effects. B: Representative images of invading T24 cells after transfection with si-NTC, sieNOS, or si-iNOS. C and D: Quantification of T24 cell invasion (C) and $\mathbf{J} 82$ cell invasion (D) after siRNA transfection. E: Representative images of cell migration assay performed with si-RNA transfected T24 cells. The first dotted line indicates the cell migration at 0 hour, and the second dotted line indicates cell migration at 24 hours. $\mathbf{F}-\mathbf{H}$ : Quantification of migration data after siRNA transfection in T24, J82, and RT112 cells. I: Application of NOS inhibitors L-Name and $1400 \mathrm{~W}$ and the soluble guanylyl cyclase inhibitor ODQ reduce bladder cancer cell migration in T24 cells. Inhibition effects can be overcome by co-application of NO or CGMP analogues. Data are expressed as means \pm SEM. $n$ $=3 .{ }^{*} P<0.05,{ }^{* * *} P<0.001$, and $* * * * P<0.0001$ ( $t$-test). Original magnification, $\times 100$. Deta, Deta-NONOate.

development of invasive disease, eNOS expression only increased in the presence of invasive disease.

Semiquantitative analysis of eNOS and iNOS expression in the progression spectrum of human bladder cancer found a progressive increase in the expression of these proteins from normal urothelium to invasive and metastatic disease. Specifically, eNOS increased protein expression from normal urothelium (mean value of 0 ) to invasive disease (mean value of $1.549 ; P=0.0016$ ) as well as from invasive disease to lymph node metastases (mean value of 1.772; $P=0.013$ ) (Figure 3B). By contrast, iNOS had increased protein expression from normal urothelium (mean value of 0 ) to invasive disease (mean value of 1.754; $P=0.0013$ ) (Figure 3C) but no further significant increase in metastatic carcinoma (mean value of 1.684; $P=0.5034$ ). Comparison of primary urothelial carcinoma in the bladder found that higher tumor expression of eNOS was more commonly associated with tumors that developed metastases (mean value of 1.689) versus those that did not (mean value of 1.231; $P<0.0001)$. This association was not seen with iNOS expression (mean value of 1.768 in metastatic tumor; mean value of 1.723 in nonmetastatic tumor) (Figure 3, D and E).

\section{Evaluation of NO Effects on Migration and Invasion Using NO Donor and Scavenger Compounds}

To test the effect of the diffusible, short half-life NO molecule on bladder cancer cell migration and invasion, a donor and scavenger approach was used to increase or decrease the local levels of NO, respectively. Application of cobinamide, a NO scavenger, found a dose-dependent reduction in T24 bladder cancer cell migration to $71 \%$ of control levels $(P<0.001)$ (Figure 4, A and B) and a dose-dependent reduction in invasion to $16 \%$ of control levels $(P<0.001)$ (Figure $4, C$ and D). By 


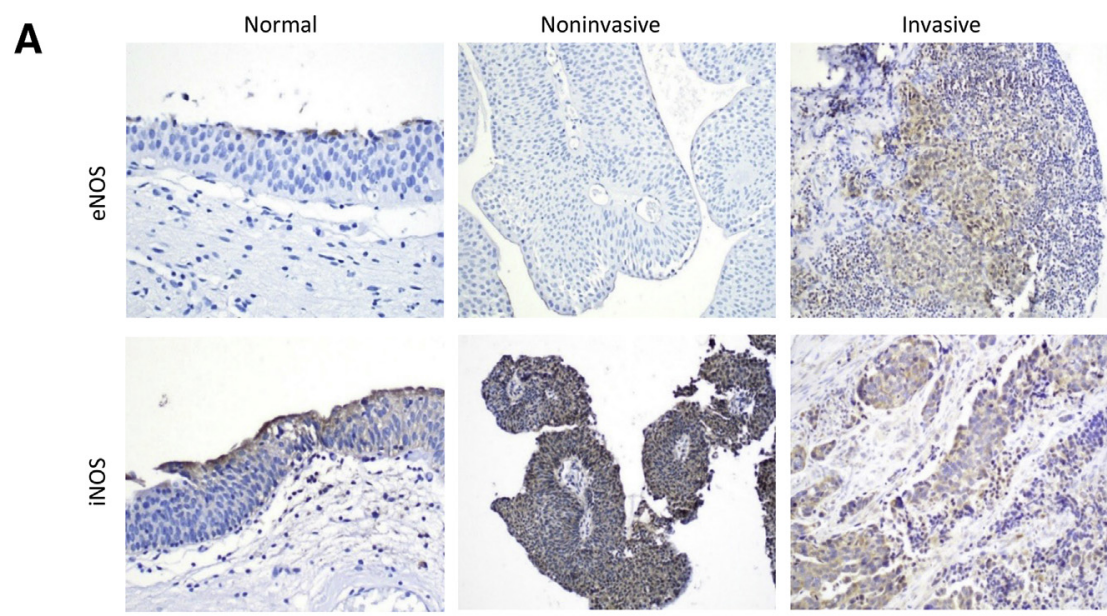

B

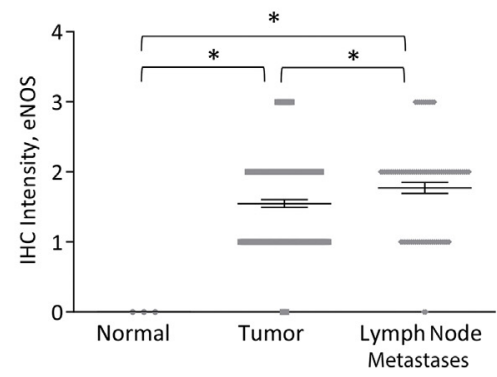

D

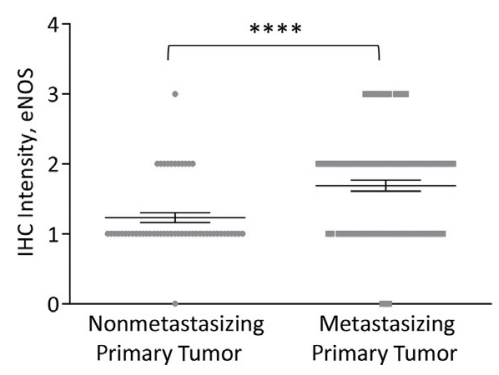

C

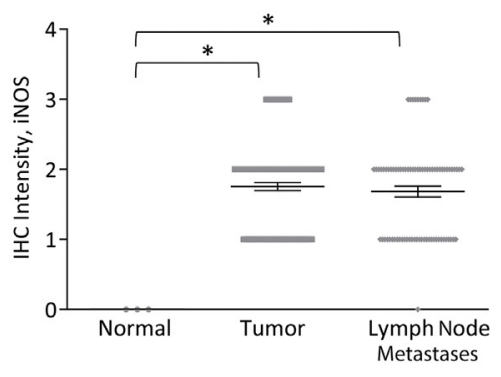

E

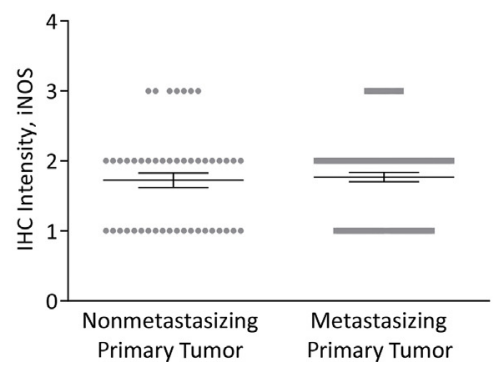

Figure 3 Inducible nitric oxygen synthase (iNOS) and endothelial nitric oxide synthase (eNOS) expression shows a progressive increase in expression with advancing human bladder cancer stage. A: Normal urothelium and noninvasive and invasive urothelial carcinoma were assessed for eNOS and iNOS expression by immunohistochemistry (IHC). B: Evaluation of intensity of IHC shows an increase in eNOS expression in urothelial tumor relative to normal urothelium, with an additional increase in expression within paired lymph node metastasis. C: iNOS expression is primarily increased in urothelial cancer relative to normal urothelium, without an additional increase in metastatic deposits. D and E: eNOS expression but not iNOS expression in primary urothelial carcinoma tumors is associated with a greater risk of metastasis. Data are expressed as means \pm SEM $(\mathbf{B}-\mathbf{E})$. $n=3 .{ }^{*} P<0.05,{ }^{*} * * P<0.0001$. Original magnification, $\times 100($ A). contrast, application of Deta-NONOate significantly increased T24 bladder cancer cell migration to $133 \%$ of the control levels $(P<0.001)$ (Figure 4E) and increased invasion to $179 \%$ of the control levels $(P<0.001)$ (Figure $4 \mathrm{~F})$. Similar results were seen in $\mathrm{J} 82$ bladder cancer cells $(P<0.001)$ (Supplemental Figure S3, A-D). Up to the final concentration of $50 \mu \mathrm{mol} / \mathrm{L}$, NO donor or scavenger compounds had a significant effect on both cancer cell migration and invasion, but not on cell viability $(P<0.001)$ (Supplemental Figure S4, A-D).

\section{Invasive Tips of Bladder Cancer Cells, Invadopodia,} Show Enrichment in NOS Proteins and mTORC2 Activity

Given that the NO pathway could affect bladder cancer cell migration and invasion, experiments were conducted to determine how cytoskeletal or cell protrusion processes contribute to this effect. First, the effect of NO on F-actin reorganization was evaluated, which is a critical step to effective cell migration and invasion. ${ }^{38}$ Staining of F-actin in serumstarved T24 cells found a flattened cell morphology and uniformly distributed actin fibers, with minimal cell protrusions (Figure 4A). After 1-hour serum stimulation, the actin cytoskeleton developed aggregates at the cell periphery and increased cell protrusions (Figure 5A). Exposure of cells to the NO donor Deta-NONOate in serum-free media for 1 hour increased actin at the cell periphery and cell protrusions, mirroring the effects of serum application (Figure 5A). By contrast, co-application of the NO scavenger cobinamide reduced seruminduced actin protrusions and promoted cell elongation (Figure 5A). 


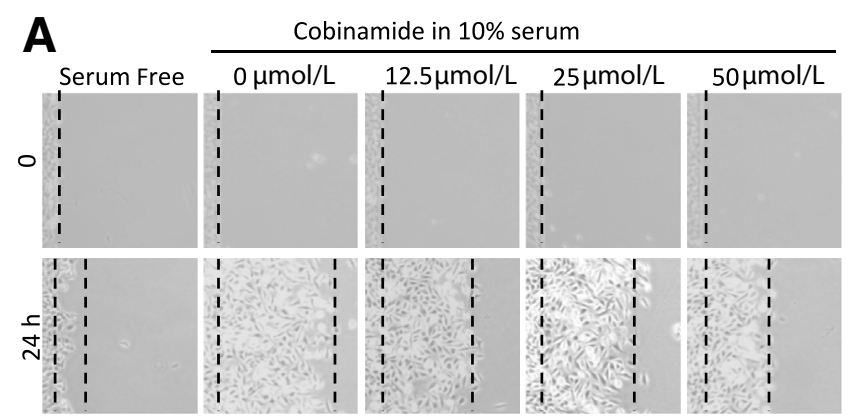

C

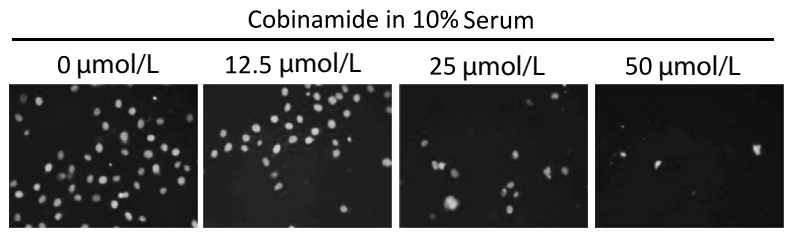

$\mathbf{E}$

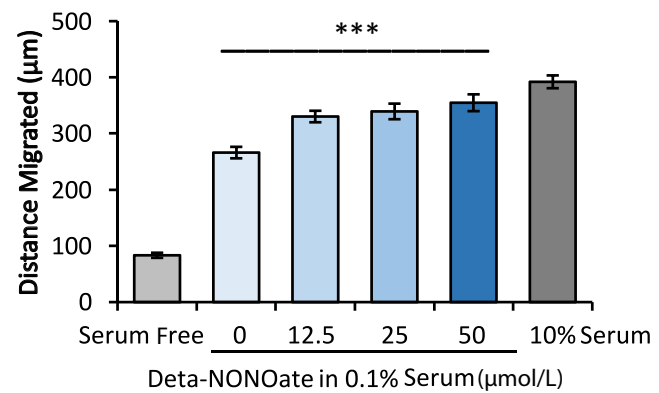

B

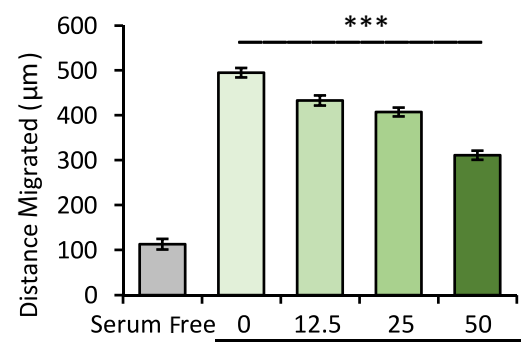

Cobinamide in $10 \%$ Serum $(\mu \mathrm{mol} / \mathrm{L})$

D

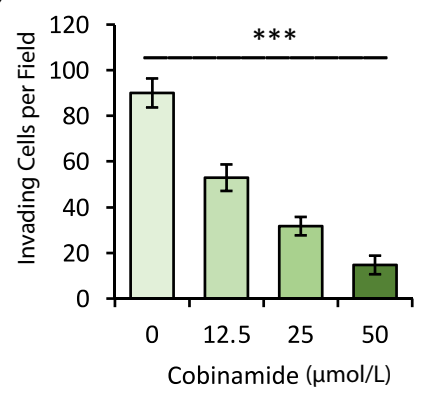

$\mathbf{F}$

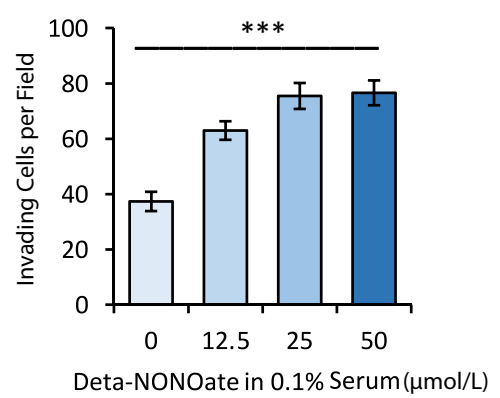

Figure 4 Nitric oxide (N0) scavenger and donor application confirmed that N0 is involved in motility effects. A and B: Representative images of T24 cells with increasing concentrations of the NO scavenger cobinamide during a migration assay (the first dotted line indicates the cell migration at 0 hour, and the second dotted line indicates cell migration at 24 hours) (A) and quantitation of these effects (B). C and D: Representative images of T24 invading cell number with increasing cobinamide concentration (C) and quantitation of these effects (D). E: Migration distance increases with increasing concentration of the N0 donor Deta-NONOate. F: Similar effects were with Deta-NONOate application in the invasion assay. Data are expressed as means \pm SEM (B and $\mathbf{D}-\mathbf{F}) . n=3$. $* * * P<0.001$ (analysis of variance). Original magnification, $\times 100(\mathbf{A}$ and $\mathbf{C})$.

Because NO has a short half-life and a limited diffusion radius in aqueous media of 100 to $500 \mu \mathrm{m},{ }^{39}$ signaling effects of this molecule likely occur in the immediate microenvironment. One property of invasive cancer cells that mediates the leading edge of invasion at the cellular level is the formation of actin-rich membrane protrusions called invadopodia. ${ }^{24}$ Given the proinvasive effects of mTORC2 and NO, as well as F-actin alterations in response to $\mathrm{NO}$ donor activity, we next examined the role of mTORC2 and $\mathrm{NO}$ in invadopodia formation. To perform this analysis, invadopodia were captured and separated from the cell bodies after invasion through a 3.0$\mu \mathrm{m}$ membrane filter (Figure 5B). Separation of invadopodia and cell bodies in T24 cells was confirmed using immunoblot analysis of invadopodia-enriched Rac1, which also represents an mTORC2 target $^{4}$ and cell body-enriched histone $\mathrm{H}^{24}$ (Figure 5C). Although eNOS had comparable expression in both the cell body and invadopodia, iNOS was enriched within invadopodia (Figure 5C). Differential expression of kinase targets of the mTOR complexes mTORC1 and mTORC2 was also identified. Specifically, the mTORC1 phosphorylation target S6 (pS6) was enriched in bladder cancer cell bodies, whereas the mTORC2 phosphorylation target AKT Ser473 (pAKT Ser473) was enriched in invadopodia. Confirmation of subcellular localization of iNOS to invadopodia was performed using immunofluorescence staining (Supplemental Figure S5A). 


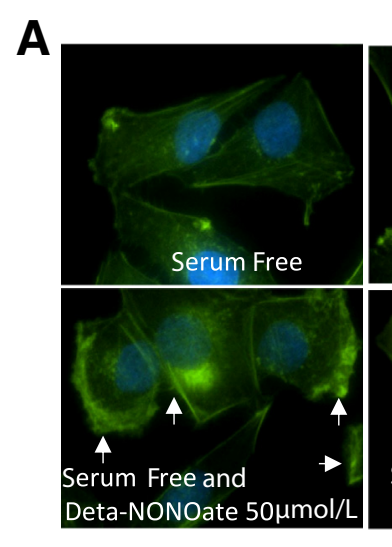

D

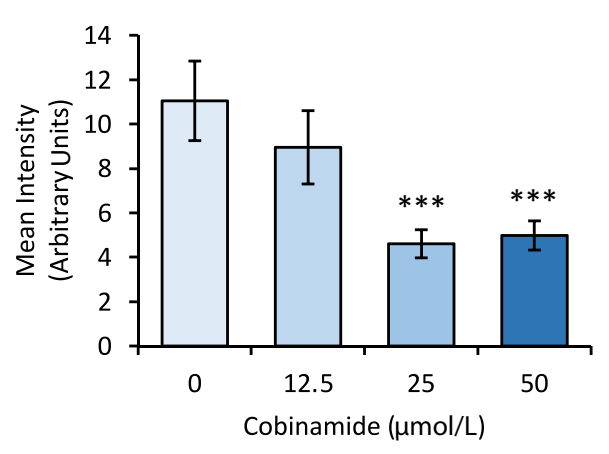

F

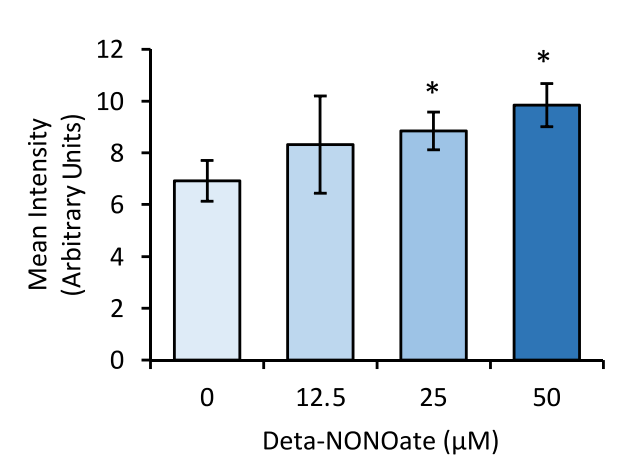

B

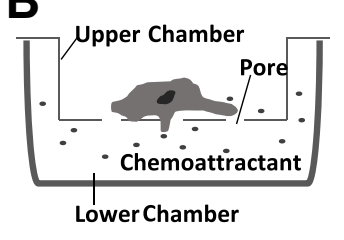

C CB IN

Rictor

iNOS

eNOS

pAKT (Ser 473)

AKT

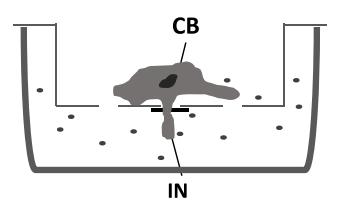

p-S6 Ser 235-236

S6

Rac1

Histone $\mathrm{H} 3$

Actin

E

Cobinamide, $10 \%$ Serum
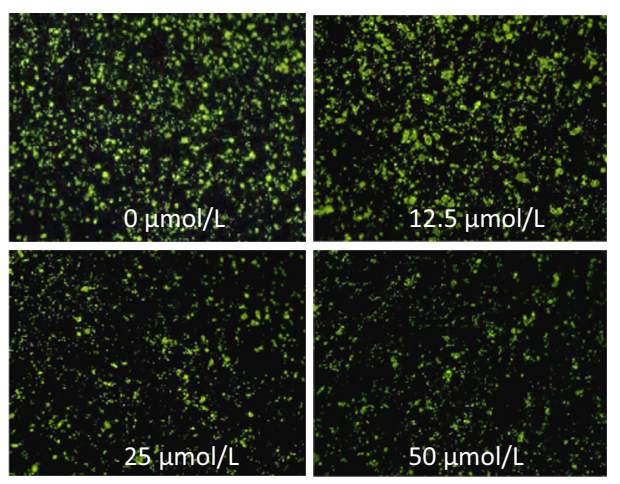

G

Deta-NONOate, $0.1 \%$ Serum
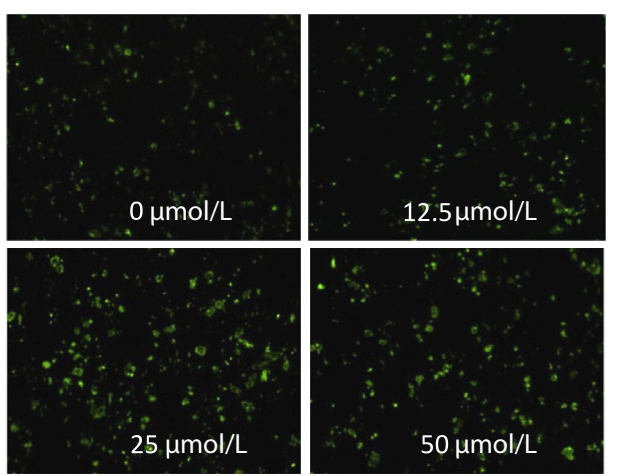

Figure 5 Inducible nitric oxide synthase (iNOS) and mammalian target of rapamycin complex 2 (mTORC2) activity is enriched in invadopodia and may mediate local effects. A: Actin (green) shows rearrangement after cobinamide or Deta-NONOate treatment in T24 cells. The arrows indicated the aggregates developed by actin cytoskeleton rearrangement. Cell nuclei are shown in blue (DAPI stain). Serum-free and serum-containing media were used as controls. B: Schematic of invadopodia assay. C: Immunoblot of rictor (mTORC2 component), iNOS, endothelial nitric oxide synthase (eNOS), phospho-AKT (pAKT) (Ser473) (mTORC2 target), total AKT, phospho-S6 (pS6) Ser235/236 (mTORC1 target), total S6, Rac1 (invadopodia marker), and histone H3 (cell body marker) in cell body (CB) and invadopodia (IN) fractions of untreated T24 cells. D: Quantitation shows a dose-dependent reduction in invadopodia formation with cobinamide treatment of T24 cells. E: Images showing cobinamide effect in one of three independent experiments. F: By contrast, quantitation shows a dose-dependent increase in invadopodia formation as evident with Deta-NONOate application to T24 cells. G: Deta-NONOate images from one representative experiment of three. Data are expressed as means $\pm \mathrm{SEM}(\mathbf{B}-\mathbf{D}$ and $\mathbf{F}) . n=3$. ${ }^{*} P<0.05,{ }^{*} * P<0.001$ (t-test). Original magnification, $\times 100(\mathbf{A}, \mathbf{E}$, and $\mathbf{G})$.

Finally, the study analyzed whether local NO levels influence invadopodia formation. Comparison of increasing concentrations of cobinamide added to the upper invadopodia chamber media of T24 cells to scavenge NO-reduced invadopodia formation in a stepwise manner $(P<0.001)$ (Figure 5, D and E), whereas addition of Deta-NONOate to the lower invadopodia chamber increased the number of invadopodia $(P<0.05)$ (Figure $5, \mathrm{~F}$ and $\mathrm{G})$. 
mTORC2 Activity Regulates Invadopodia Formation, eNOS and iNOS Expression, and cGMP Production in Invadopodia

Although eNOS, iNOS, and mTORC2 components and activity were localized to invadopodia, the interaction among these pathways was not clear. To test whether a directional cell signaling relationship exists in the context of bladder cancer cell invasion, eNOS or iNOS were first silenced, and changes in mTOR kinase target phosphorylation were evaluated. si-eNOS and si-iNOS cells did not have significant changes in pS6 and pAKT Ser473 in T24 bladder cancer cell invadopodia or cell body fractions, suggesting that neither eNOS nor iNOS functions upstream of mTOR complexes (Figure 6A).

Next, the converse relationship was tested by evaluating the effect of rictor silencing on eNOS and iNOS expression and signaling. Silencing of rictor using pooled siRNA (sirictor) in T24 cells found a reduction of rictor protein and a concordant reduction in pAKT Ser473, without effects on pS6 (Figure 6B). Rictor-specific silencing also reduced iNOS and eNOS expression levels in invadopodia by $33 \%$ and $8 \%$, respectively (Figure 6, C and D). Silencing of rictor, eNOS, or iNOS also reduced the total number of invadopodia formed as visualized by crystal violet stain (Supplemental Figure S5B). Treatment of cells with 50 $\mu \mathrm{mol} / \mathrm{L}$ cobinamide during a 1-hour period decreased cGMP levels to $30 \%$ of control, whereas $50 \mu \mathrm{mol} / \mathrm{L}$ DetaNONOate increased cGMP levels to $164 \%$ of control $(P<0.05)$ (Figure 6E). We also examined the effect of rictor silencing on cGMP levels in T24 cells. si-rictor decreased cGMP levels to $36 \%$ of si-NTC cells. si-eNOS and si-iNOS reduced cGMP levels to $50 \%$ and $38 \%$ of siNTC cells, respectively $(P<0.05)$, similar to the effects seen with si-rictor (Figure 6F).

\section{Silencing of Rictor and iNOS Reduce Experimentally- Induced Metastases in a Zebrafish Model}

Because mTORC2 and iNOS activity strongly influence invasive behavior in bladder cancer cells, the study sought to test the effects of these two factors in the establishment of metastasis using a zebrafish model. In this system, injection of fluorescently labeled bladder cancer cells into the perivitelline cavity leads to the development of experimentinduced metastasis within a short period. First, the metastatic ability of the less invasive RT4 and RT112 cells was compared to the highly invasive J82, T24, and UM-UC-3 cells to confirm that higher rates of metastasis correlated with invasive behavior in this model (Figure 7A). To compare the effects of rictor and iNOS on experimentinduced metastasis, a stable transfection of UM-UC-3 bladder cancer cells was performed with shRNA-specific for rictor or iNOS, after which the cells were fluorescently labeled red. These cells were injected at an equal ratio with cells transfected with NTC shRNA, which were fluorescently labeled green, to allow comparison of the metastatic behavior of cells within a single fish (Figure 7B). Single cells were counted in these experiments. Rictor and iNOS silencing reduced metastases to $49 \%(P=0.014)$ and 29\% $(P=0.012)$ of NTC-transfected control cells (Figure 7, C and D), respectively. In addition, sh-rictor and sh-iNOS cells had a reduction in cGMP levels to $33 \%$ and $28 \%(P<0.05)$ of NTC-control UM-UC-3 cells (Figure 7E), respectively.

\section{Discussion}

Invasive disease progression is a primary driver of poor outcomes in bladder cancer, ${ }^{2}$ with signaling through the mTORC2 pathway representing a major driver of invasion. However, little is known regarding the downstream effectors of mTORC2 in this setting. Given that prior research has demonstrated alterations in metabolic pathways, including arginine, in invasive bladder cancer, ${ }^{7,32}$ this study sought to determine whether arginine and its derivative NO are relevant to the invasive process. Arginine metabolism occurs through arginase or the NOS family of proteins. Whereas arginase produces urea, ornithine, polyamines, glutamate, and proline, which can promote cell growth, ${ }^{40}$ the NOS enzyme family produces NO, which can enhance cell motility. ${ }^{8}$ Given the potential role of $\mathrm{NO}$ in bladder cancer invasion, the current study focused on the effect of $\mathrm{NO}$ and its interface with the mTORC2 signaling pathway in this context.

Human bladder cancer specimens were used to identiy a stepwise increase in eNOS and iNOS expression with progression from noninvasive to invasive disease, which supports data from prior studies. ${ }^{7,8}$ However, some differences in expression were noted that could indicate unique functions of these isoforms. Specifically, eNOS was expressed only after invasion and/or establishment of metastatic disease, suggesting a potential late-stage effect of NO production in cancer cell dissemination. By contrast, iNOS expression was also increased in noninvasive bladder cancers, suggesting a possible role of iNOS in mediating early invasive behavior. It has been reported that iNOS-positive patients with bladder cancer have greater recurrences compared with iNOS-negative patients $^{13}$ and that a specific eNOS polymorphism predisposes patients to tumor recurrence and progression, ${ }^{41}$ indicating their utility in clinical outcomes. In future studies, topographic localization of these proteins within tumors, especially at invasive fronts, can potentially provide more information about their role in the progression of bladder cancer.

The study also identified increased iNOS and eNOS expression in highly invasive bladder cancer cell lines compared with less invasive cell lines. To determine whether the increased level of expression corresponds to invasive behavior, NOS enzyme silencing and NOS 


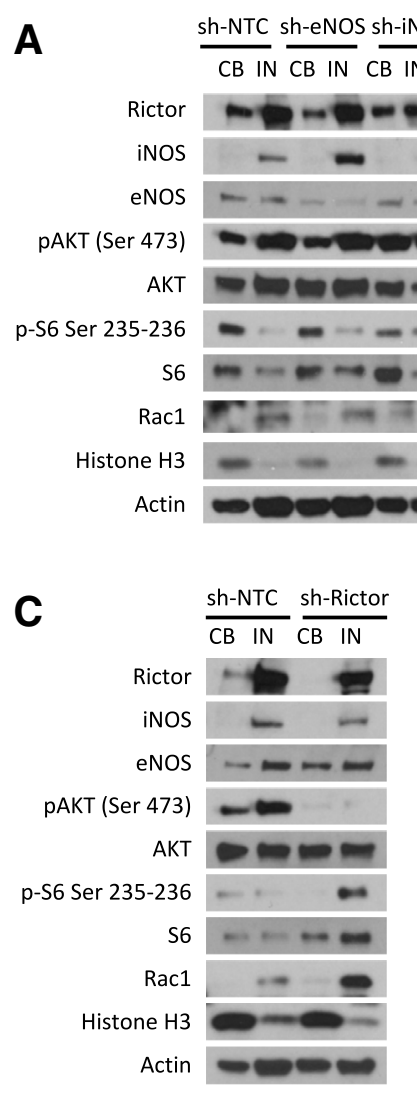

E

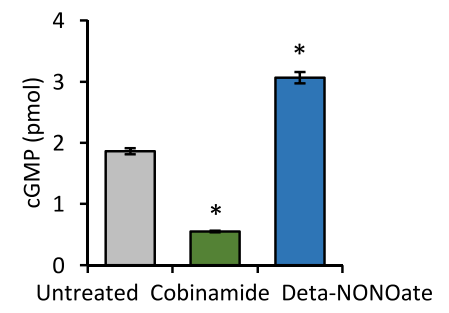

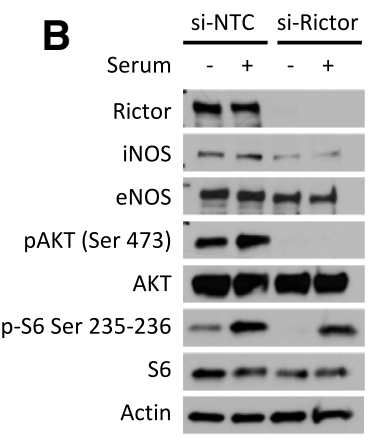

D

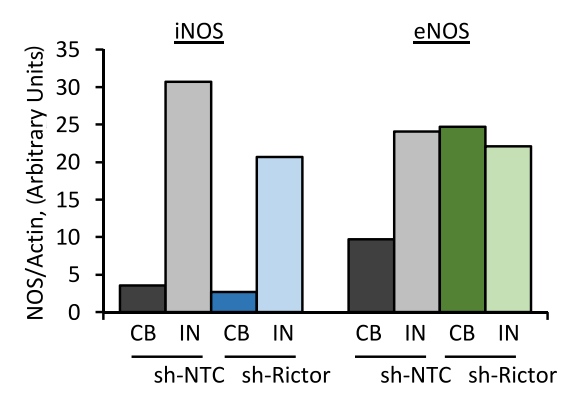

$\mathbf{F}$

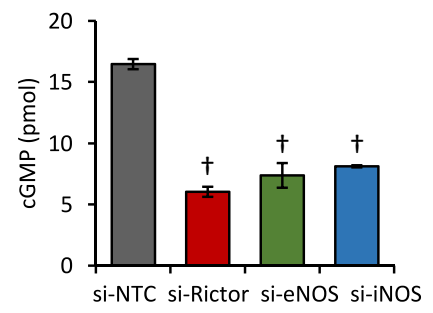

Figure 6 Mammalian target of rapamycin complex 2 (mTORC2) activity regulates endothelial nitric oxide synthase (eNOS) and inducible nitric oxide synthase (iNOS) expression and CGMP formation. A: Immunoblot of rictor, iNOS, eNOS, phospho-AKT (pAKT0 Ser473, total AKT, phosphoS6 (p-S6) Ser235/236, and total S6 in T24 cells stably transfected with nontargeting control (NTC), eNOS, or iNOS shRNA. Rac1 was used as an invadopodia control and histone $\mathrm{H} 3$ as a cell body control. B: Immunoblot comparison of siRNA NTC (si-NTC) and siRNA rictor (si-rictor) transfected T24 cells, with (plus sign) and without (minus sign) serum stimulation, shows that rictor ablation reduces iNOS and eNOS protein expression. Although elimination of mTORC2 activity through lack of pAKT Ser473 signal is evident with rictor silencing, mTORC1 activity, by induction of $\mathrm{p}-\mathrm{S} 6$ with serum stimulation, remains intact. $\mathbf{C}$ and $\mathbf{D}$ : Stable transfection of T24 cells with shRNA NTC (sh-NTC) or shRNA rictor (sh-rictor) confirms ablation of mTORC2 signaling effects, with a modest reduction in iNOS and eNOS proteins (C), as confirmed by NOS/actin ratios analyzed by densitometry (D). E: T24 cells show changes in cGMP levels treated with $50 \mu \mathrm{mol} / \mathrm{L}$ cobinamide or Deta-NONOate. F: Rictor and NOS silencing reduce cGMP levels in T24 cells. Data are expressed as means \pm SEM. $n=3 .{ }^{*} P<0.05$ versus untreated (t-test); $P<0.05$ versus si-NTC ( $t$-test). inhibition was tested, and both eNOS and iNOS expression were shown to be important for bladder cancer cell migration and invasion. To confirm that these effects were caused by the NOS product NO, the reversible NO scavenger cobinamide was used to ablate NO signaling and the NO donor Deta-NONOate was used to enhance NO signaling in identical assays. The results of these studies indicate that NO can enhance bladder cancer cell migration and invasion, with a resultant increase in cGMP signaling in this context, suggesting a cGMP-dependent mechanism of bladder cancer cell invasion. Taken together, these findings indicate an additional role for arginine in advanced bladder cancer in which it can promote bladder cancer cell invasion through the activity of NOS enzymes and production of NO and resultant cGMP second messenger signaling.

NO has the capacity to function as an intracellular signaling molecule but can also traverse the lipid bilayer of the cell membrane to act as an extracellular signaling molecule. ${ }^{42}$ In support of this, NO has autocrine and paracrine cell effects in other cancer systems through its presence in local microenvironment. ${ }^{43}$ In addition, the short half-life and limited diffusion radius of NO imply that the effects of $\mathrm{NO}$ are often in the immediate vicinity of NO production. Given that NO enhanced bladder cancer cell invasion, the subcellular localization of NOS enzymes in invading cancer cells was assessed to identify a likely site of NO activity within the cell. The approach of separating and analyzing bladder cancer cell bodies and invadopodia, which represent the actin-rich invasive tips of cells, ${ }^{24}$ was used to determine subcellular localization.

Whereas eNOS was present in the cell body and the invadopodia, iNOS was enriched within the invadopodia fraction. This finding conceptually supports prior work that suggests NOS proteins localize to the plasma membrane in certain cell types and may interact with caveolae 

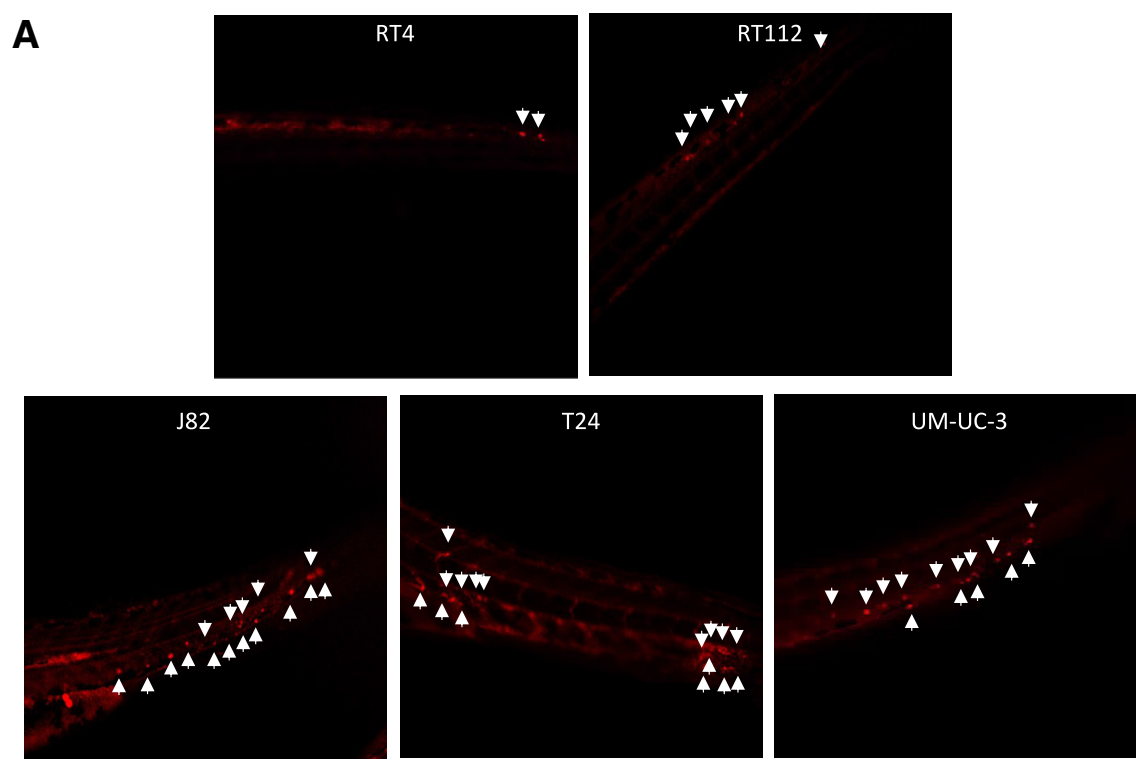

B
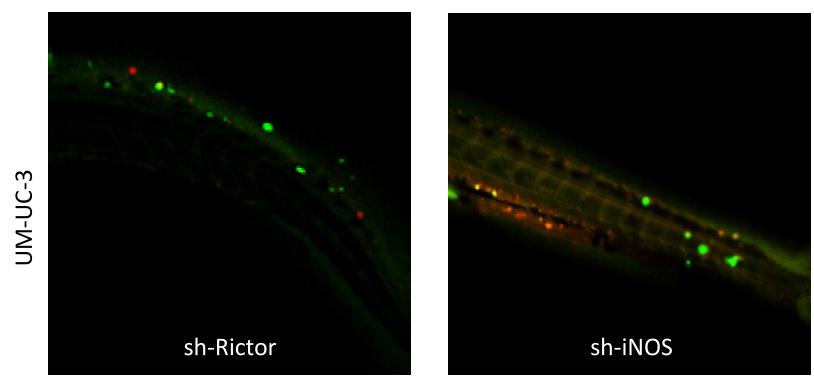

C

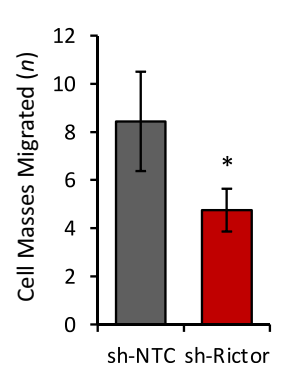

D

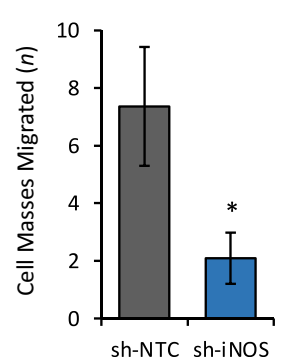

E

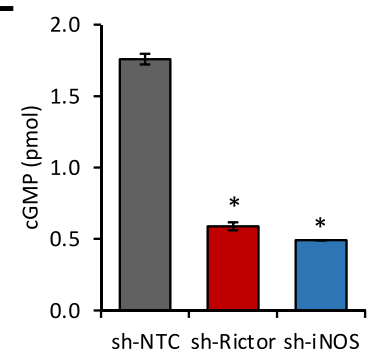

Figure 7 Endothelial nitric oxide synthase (eNOS), inducible nitric oxide synthase (iNOS), and rictor are important in the establishment of zebrafish tail vein metastasis. A: Representative images show that fluorescently labeled, highly invasive J82, T24, and UM-UC-3 bladder cancer cells demonstrate a higher number of zebrafish tail vein metastasis compared with the less invasive RT4 and RT112 cells. The metastasized cancer cells were indicated by arrows. Embryos were used at 48 hours post fertilization, and injections were into the perivitelline cavity. B: UM-UC-3 cells transfected with either shRNA rictor (sh-rictor) or shRNA iNOS (sh-iNOS) (red) were co-injected with control shRNA NTC (shNTC) cells (green) into zebrafish to compare effects of rictor and iNOS on frequency of metastasis. $C$ and D: Quantitation of metastasis by manual counting. E: cGMP levels were also decreased with either shrictor or sh-iNOS transfection of UM-UC-3 cells. Data are expressed as means \pm SEM $(\mathbf{C}-\mathbf{E}) . n=3$. ${ }^{*} P<0.05$ for target shRNA-treated cells versus control sh-NTC cells ( $t$-test). Original magnification, $\times 100$ (A and B). and the associated caveolin-1 protein, ${ }^{6,43}$ which promote invadopodia formation in breast cancer cells. ${ }^{44}$ Use of cobinamide and Deta-NONOate confirmed that NO promotes invadopodia formation in bladder cancers. Furthermore, application of the NO donor to the lower invadopodia chamber increased the overall number of invadopodia, suggesting that NO may function as a local chemoattractant at invading cancer cell tips. Although not tested in the current study, additional NO contribution from adjacent cells in the bladder wall microenvironment may further influence directional invasion of bladder cancer cells.

Given that mTORC2 activity can drive bladder cancer cell invasion ${ }^{4}$ and NO appears to be a key mediator of invadopodia formation, the relationship between these two factors was analyzed. Analysis of cell fractions for mTORC2 signaling components identified preferential expression within invadopodia of the mTORC2 subunit rictor, as well as an mTORC2 effector Rac1. ${ }^{4}$ Activation of mTORC2 signaling promotes F-actin reorganization and enhanced cell protrusions in bladder cancer cells, which is similar to effects identified with NO in this study. ${ }^{45}$ Furthermore, silencing of rictor reduced eNOS and iNOS protein levels in whole cell lysates and invadopodia, suggesting that $\mathrm{mTORC} 2$ can regulate NOS protein expression and ultimately NO production. Mechanisms that may explain the relationship between mTORC2 activity and NOS protein expression include effects of mTOR activity on NOS mRNA translation ${ }^{46}$ or regulation of hypoxia- inducible factor and NOS mRNA transcription. ${ }^{47-49}$ Indeed, both eNOS and iNOS contain hypoxia response elements within their promoter 
regions. ${ }^{50,51}$ Finally, the study used a transparent zebrafish metastasis model, which has been previously reported to capture invasive and metastatic behavior in cancer cell modeling. ${ }^{29,30}$ Both rictor and iNOS enhanced experimentally-induced metastatic potential in this model at a similar rate, confirming a role for both factors in cancer cell progression, although hierarchical signaling was not confirmed in this system.

The results of this study expand on the prior research that found that mTORC2 activity is important in bladder cancer invasion. ${ }^{4,32,52}$ Within the literature, relatively limited information is available about known mTORC2 effectors, and this topic has been a major focus of recent work in our group and others. Several mTORC2 targets include protein kinase $\mathrm{C}^{53}$ direct ribosome interaction, ${ }^{54}$ the cystine-glutamate transporter, ${ }^{55}$ RhoGTPases, ${ }^{4}$ and caveolin- $1,{ }^{5}$ among others. To our knowledge, this is the first report that identifies NOS enzymes and NO as downstream effectors of mTORC2. In addition, this study represents the first analysis of mTORC 2 and NO in cancer cell invadopodia, which may lend itself to consideration of new therapeutic approaches for bladder cancer and other cancers in general. Given that mTOR is known to be overexpressed in invasive bladder cancer but mTOR inhibitors in isolation have not been efficacious in bladder cancer therapy ${ }^{56}$ new knowledge related to mTOR function is important in designing new therapies. Cobinamide has already been tested as a cyanide antidote in mice, rabbit, and swine models ${ }^{27,57,58}$ and has been demonstrated to reverse cyanide poisoning with intramuscular administration in mice. ${ }^{27}$ Cobinamide is expected to be tested in Phase I human clinical trials in the near future (Grantome, http:// grantome.com/grant/NIH/U01-NS058030-10, last accessed May 24, 2021). New-generation mTOCR2-specific inhibitors that have recently been reported ${ }^{59,60}$ can potentially be useful combined with NOS inhibition, an approach that can be tested in future studies.

In summary, this study demonstrated the ability of mTORC2 to regulate eNOS and iNOS expression and a role for mTORC2 and NO signaling in invadopodia formation. These findings suggest that local production of NO can regulate bladder cancer cell invasion at the subcellular level, which can therefore affect cancer cell invasion and metastasis. Future studies will test the mechanism of mTORC2 regulation of the NOS signaling pathway and determine the potential value of NO blockade in bladder cancer cell therapy.

\section{Acknowledgment}

We thank Felicia Watson for her work on zebrafish mating.

\section{Author Contributions}

D.E.H. and D.S. conceived and designed the experiments; D.S., H.W., D.S., and D.E.C. performed the experiments and interpreted and analyzed the data; R.L.K. and G.R.B. provided samples, interpreted the data, and contributed to the critical reading of the manuscript; J.H. interpreted data and edited the manuscript; and D.E.H. and D.S. interpreted the data and wrote the manuscript. All authors read and provided feedback on the manuscript.

\section{Supplemental Data}

Supplemental material for this article can be found at http://doi.org/10.1016/j.ajpath.2021.08.002.

\section{References}

1. American Cancer Society: Cancer Facts \& Figures 2018. Atlanta, American Cancer Society, 2018

2. Sternberg CN: Muscle invasive and metastatic bladder cancer. Ann Oncol 2006, 17(Suppl 10):23-30

3. American Cancer Society: Survival Rates for Bladder Cancer Atlanta, GA, American Cancer Society, 2018

4. Gupta S, Hau AM, Beach JR, Harwalker J, Mantuano E, Gonias SL, Egelhoff TT, Hansel DE: Mammalian target of rapamycin complex 2 (mTORC2) is a critical determinant of bladder cancer invasion. PLoS One 2013, 8:e81081

5. Campbell L, Jasani B, Edwards K, Gumbleton M, Griffiths DF: Combined expression of caveolin-1 and an activated AKT/mTOR pathway predicts reduced disease-free survival in clinically confined renal cell carcinoma. Br J Cancer 2008, 98:931-940

6. Hau AM, Gupta S, Leivo MZ, Nakashima K, Macias J, Zhou W, Hodge A, Wulfkuhle J, Conkright B, Bhuvaneshwar K, Rao S, Madhavan S, Petricoin EF 3rd, Hansel DE: Dynamic regulation of caveolin-1 phosphorylation and caveolae formation by mammalian target of rapamycin complex 2 in bladder cancer cells. Am J Pathol 2019, 189:1846-1862

7. Sahu D, Lotan Y, Wittmann B, Neri B, Hansel DE: Metabolomics analysis reveals distinct profiles of nonmuscle-invasive and muscleinvasive bladder cancer. Cancer Med 2017, 6:2106-2120

8. Fukumura D, Kashiwagi S, Jain RK: The role of nitric oxide in tumour progression. Nat Rev Cancer 2006, 6:521-534

9. Sahu D, Gupta S, Hau AM, Nakashima K, Leivo MZ, Searles SC, Elson P, Bomalaski JS, Casteel DE, Boss GR, Hansel DE: Argininosuccinate synthetase 1 loss in invasive bladder cancer regulates survival through general control nonderepressible 2 kinasemediated eukaryotic initiation factor 2alpha activity and is targetable by pegylated arginine deiminase. Am J Pathol 2017, 187: 200-213

10. Lin Z, Chen S, Ye C, Zhu S: Nitric oxide synthase expression in human bladder cancer and its relation to angiogenesis. Urol Res 2003, 31:232-235

11. Ehsan A, Sommer F, Schmidt A, Klotz T, Koslowski J, Niggemann S, Jacobs G, Engelmann U, Addicks K, Bloch W: Nitric oxide pathways in human bladder carcinoma: the distribution of nitric oxide synthases, soluble guanylyl cyclase, cyclic guanosine monophosphate, and nitrotyrosine. Cancer 2002, 95:2293-2301

12. Wolf $\mathrm{H}$, Haeckel C, Roessner A: Inducible nitric oxide synthase expression in human urinary bladder cancer. Virchows Archiv 2000, 437:662-666

13. Sandes EO, Faletti AG, Riveros MD, Vidal Mdel C, Gimenez L, Casabe AR, Eijan AM: Expression of inducible nitric oxide synthase in tumoral and non-tumoral epithelia from bladder cancer patients. Nitric Oxide 2005, 12:39-45

14. Koskela LR, Poljakovic M, Ehren I, Wiklund NP, de Verdier PJ: Localization and expression of inducible nitric oxide synthase in 
patients after BCG treatment for bladder cancer. Nitric Oxide 2012, 27:185-191

15. Klotz T, Bloch W, Jacobs G, Niggemann S, Engelmann U, Addicks K: Immunolocalization of inducible and constitutive nitric oxide synthases in human bladder cancer. Urology 1999, 54: 416-419

16. Shochina M, Fellig Y, Sughayer M, Pizov G, Vitner K, Podeh D, Hochberg A, Ariel I: Nitric oxide synthase immunoreactivity in human bladder carcinoma. Mol Pathology 2001, 54:248-252

17. Fathian-Sabet B, Bloch W, Klotz T, Niggemann S, Jacobs G, Addicks K, Engelmann U: Localization of constitutive nitric oxide synthase isoforms and the nitric oxide target enzyme soluble guanylyl cyclase in the human bladder. J Urol 2001, 165:1724-1729

18. Eijan AM, Piccardo I, Riveros MD, Sandes EO, Porcella H, Jasnis MA, Sacerdote De Lustig E, Malagrino H, Pasik L, Casabe AR: Nitric oxide in patients with transitional bladder cancer. J Surg Oncol 2002, 81:203-208

19. Kilic S, Bayraktar N, Beytur A, Ergin H, Bayraktar M, Egri M: Can the levels of nitric oxide in the urine, serum and tumor tissue be putative markers for bladder cancer? Int J Urol 2006, 13:1079-1085

20. Dong J, Cheng M, Sun H: Function of inducible nitric oxide synthase in the regulation of cervical cancer cell proliferation and the expression of vascular endothelial growth factor. Mol Med Rep 2014, 9:583-589

21. Fujita M, Imadome K, Endo S, Shoji Y, Yamada S, Imai T: Nitric oxide increases the invasion of pancreatic cancer cells via activation of the PI3K-AKT and RhoA pathways after carbon ion irradiation. FEBS Lett 2014, 588:3240-3250

22. Zhan R, Yang S, He W, Wang F, Tan J, Zhou J, Yang S, Yao Z, Wu J, Luo G: Nitric oxide enhances keratinocyte cell migration by regulating Rho GTPase via cGMP-PKG signalling. PLoS One 2015, 10:e0121551

23. Murali A, Rajalingam K: Small Rho GTPases in the control of cell shape and mobility. Cell Mol Life Sci 2014, 71:1703-1721

24. Klemke RL: Trespassing cancer cells: 'fingerprinting' invasive protrusions reveals metastatic culprits. Curr Opin Cell Biol 2012, 24: 662-669

25. Allen MD, Luong P, Hudson C, Leyton J, Delage B, Ghazaly E, Cutts R, Yuan M, Syed N, Lo Nigro C, Lattanzio L, ChmielewskaKassassir M, Tomlinson I, Roylance R, Whitaker HC, Warren AY, Neal D, Frezza C, Beltran L, Jones LJ, Chelala C, Wu BW, Bomalaski JS, Jackson RC, Lu YJ, Crook T, Lemoine NR, Mather S, Foster J, Sosabowski J, Avril N, Li CF, Szlosarek PW: Prognostic and therapeutic impact of argininosuccinate synthetase 1 control in bladder cancer as monitored longitudinally by PET imaging. Cancer Res 2014, 74:896-907

26. Johnen G, Rozynek P, von der Gathen Y, Bryk O, Zdrenka R, Johannes C, Weber DG, Igwilo-Okuefuna OB, Raiko I, Hippler J, Bruning T, Dopp E: Cross-contamination of a UROtsa stock with T24 cells-molecular comparison of different cell lines and stocks. PLoS One 2013, 8:e64139

27. Chan A, Balasubramanian M, Blackledge W, Mohammad OM, Alvarez L, Boss GR, Bigby TD: Cobinamide is superior to other treatments in a mouse model of cyanide poisoning. Clin Toxicol 2010, 48:709-717

28. Wang Y, Klemke RL: Proteomics method for identification of pseudopodium phosphotyrosine proteins. Methods Mol Biol 2012, 757:349-365

29. Stoletov K, Kato H, Zardouzian E, Kelber J, Yang J, Shattil S, Klemke R: Visualizing extravasation dynamics of metastatic tumor cells. J Cell Sci 2010, 123:2332-2341

30. Teng Y, Xie X, Walker S, White DT, Mumm JS, Cowell JK: Evaluating human cancer cell metastasis in zebrafish. BMC Cancer 2013 , $13: 453$

31. Leivo MZ, Elson PJ, Tacha DE, Delahunt B, Hansel DE: A combination of p40, GATA-3 and uroplakin II shows utility in the diagnosis and prognosis of muscle-invasive urothelial carcinoma. Pathology 2016, 48:543-549

32. Sahu D, Gupta S, Hau AM, Nakashima K, Leivo MZ, Searles SC, Elson P, Bomalaski JS, Casteel DE, Boss GR, Hansel DE: Argininosuccinate synthetase 1 loss in invasive bladder cancer regulates survival through general control nonderepressible 2 kinase-mediated eukaryotic initiation factor 2alpha activity and is targetable by pegylated arginine deiminase. Am J Pathol 2016

33. Beach JR, Hussey GS, Miller TE, Chaudhury A, Patel P, Monslow J, Zheng Q, Keri RA, Reizes O, Bresnick AR, Howe PH, Egelhoff TT: Myosin II isoform switching mediates invasiveness after TGF-betainduced epithelial-mesenchymal transition. Proc Natl Acad Sci U S A 2011, 108:17991-17996

34. Uhlen M, Fagerberg L, Hallstrom BM, Lindskog C, Oksvold P, Mardinoglu A, et al: Proteomics. Tissue-based map of the human proteome. Science 2015, 347:1260419

35. Gaetje R, Kotzian S, Herrmann G, Baumann R, Starzinski-Powitz A: Invasiveness of endometriotic cells in vitro. Lancet 1995, 346: 1463-1464

36. Peschetola V, Laurent VM, Duperray A, Michel R, Ambrosi D, Preziosi L, Verdier C: Time-dependent traction force microscopy for cancer cells as a measure of invasiveness. Cytoskeleton (Hoboken) 2013, 70:201-214

37. Carattino MD, Prakasam HS, Ruiz WG, Clayton DR, McGuire M, Gallo LI, Apodaca G: Bladder filling and voiding affect umbrella cell tight junction organization and function. Am J Physiol Ren Physiol 2013, 305:F1158-F1168

38. Liu L, Chen L, Chung J, Huang S: Rapamycin inhibits F-actin reorganization and phosphorylation of focal adhesion proteins. Oncogene 2008, 27:4998-5010

39. Thomas DD, Liu X, Kantrow SP, Lancaster JR Jr: The biological lifetime of nitric oxide: implications for the perivascular dynamics of NO and O2. Proc Natl Acad Sci U S A 2001, 98:355-360

40. Morris SM Jr: Arginine metabolism: boundaries of our knowledge. J Nutrit 2007, 137:1602s-1609s

41. Amasyali AS, Kucukgergin C, Erdem S, Sanli O, Seckin S, Nane I: Nitric oxide synthase (eNOS4a/b) gene polymorphism is associated with tumor recurrence and progression in superficial bladder cancer cases. J Urol 2012, 188:2398-2403

42. Liu X, Miller MJ, Joshi MS, Thomas DD, Lancaster JR Jr: Accelerated reaction of nitric oxide with $\mathrm{O} 2$ within the hydrophobic interior of biological membranes. Proc Natl Acad Sci U S A 1998, 95: 2175-2179

43. Williams TM, Lisanti MP: The caveolin proteins. Genome Biol 2004 $5: 214$

44. Yamaguchi H, Takeo Y, Yoshida S, Kouchi Z, Nakamura Y, Fukami K: Lipid rafts and caveolin-1 are required for invadopodia formation and extracellular matrix degradation by human breast cancer cells. Cancer Res 2009, 69:8594-8602

45. Jacinto E, Loewith R, Schmidt A, Lin S, Ruegg MA, Hall A, Hall MN: Mammalian TOR complex 2 controls the actin cytoskeleton and is rapamycin insensitive. Nat Cell Biol 2004, 6:1122-1128

46. Linke M, Fritsch SD, Sukhbaatar N, Hengstschlager M, Weichhart T: mTORC1 and mTORC2 as regulators of cell metabolism in immunity. FEBS Lett 2017, 591:3089-3103

47. Toschi A, Lee E, Gadir N, Ohh M, Foster DA: Differential dependence of hypoxia-inducible factors 1 alpha and 2 alpha on mTORC1 and mTORC2. J Biol Chem 2008, 283:34495-34499

48. Page EL, Robitaille GA, Pouyssegur J, Richard DE: Induction of hypoxia-inducible factor-1alpha by transcriptional and translational mechanisms. J Biol Chem 2002, 277:48403-48409

49. Krasnapolski MA, Lodillinsky C, Bal De Kier Joffe E, Eijan AM: Hypoxia-induced nitric oxide release by luminal cells stimulates proliferation and uPA secretion of myoepithelial cells in a bicellular murine mammary tumor. J Cancer Res Clin Oncol 2015, 141: $1727-1738$ 
50. Coulet F, Nadaud S, Agrapart M, Soubrier F: Identification of hypoxia-response element in the human endothelial nitric-oxide synthase gene promoter. J Biol Chem 2003, 278:46230-46240

51. Melillo G, Musso T, Sica A, Taylor LS, Cox GW, Varesio L: A hypoxia-responsive element mediates a novel pathway of activation of the inducible nitric oxide synthase promoter. J Exp Med 1995, 182: $1683-1693$

52. Hau AM, Leivo MZ, Gilder AS, Hu JJ, Gonias SL, Hansel DE: mTORC2 activation is regulated by the urokinase receptor (UPAR) in bladder cancer. Cell Signal 2017, 29:96-106

53. Li X, Gao T: mTORC2 phosphorylates protein kinase Czeta to regulate its stability and activity. EMBO Rep 2014, 15:191-198

54. Zinzalla V, Stracka D, Oppliger W, Hall MN: Activation of mTORC2 by association with the ribosome. Cell 2011, 144:757-768

55. Gu Y, Albuquerque CP, Braas D, Zhang W, Villa GR, Bi J, Ikegami S, Masui K, Gini B, Yang H, Gahman TC, Shiau AK, Cloughesy TF, Christofk HR, Zhou H, Guan KL, Mischel PS: mTORC2 regulates amino acid metabolism in cancer by phosphorylation of the cystine-glutamate antiporter xCT. Mol Cell 2017, 67: $128-138 . e 7$
56. Sathe A, Nawroth R: Targeting the PI3K/AKT/mTOR pathway in bladder cancer. Methods Mol Biol 2018, 1655:335-350

57. Bebarta VS, Tanen DA, Boudreau S, Castaneda M, Zarzabal LA, Vargas T, Boss GR: Intravenous cobinamide versus hydroxocobalamin for acute treatment of severe cyanide poisoning in a swine (Sus scrofa) model. Ann Emerg Med 2014, 64:612-619

58. Lee J, Mahon SB, Mukai D, Burney T, Katebian BS, Chan A, Bebarta VS, Yoon D, Boss GR, Brenner M: The vitamin B12 analog cobinamide is an effective antidote for oral cyanide poisoning. J Med Toxicol 2016, 12:370-379

59. Benavides-Serrato A, Lee J, Holmes B, Landon KA, Bashir T, Jung ME, Lichtenstein A, Gera J: Specific blockade of Rictor-mTOR association inhibits mTORC2 activity and is cytotoxic in glioblastoma. PLoS One 2017, 12:e0176599

60. Werfel TA, Wang S, Jackson MA, Kavanaugh TE, Joly MM, Lee LH, Hicks DJ, Sanchez V, Ericsson PG, Kilchrist KV, Dimobi SC, Sarett SM, Brantley-Sieders DM, Cook RS, Duvall CL: Selective mTORC2 inhibitor therapeutically blocks breast cancer cell growth and survival. Cancer Res 2018, 78: $1845-1858$ 